\title{
Early Postoperative Hypoalbuminaemia as a Risk Factor for Postoperative Pneumonia Following Hip Fracture Surgery
}

This article was published in the following Dove Press journal: Clinical Interventions in Aging

\section{Kyun-Ho Shin Jae-Joong Kim Sei-Wook Son Kyo-Sun Hwang Seung-Beom Han}

Department of Orthopaedic Surgery, Anam Hospital, Korea University College of Medicine, Seoul, South Korea
Correspondence: Seung-Beom Han Korea University College of Medicine, 73 Inchon-Ro, Sungbuk-gu, Seoul 0284I, South Korea

Tel +82-2-920-5924

Fax +82-2-924-247।

Email oshan@korea.ac.kr
Purpose: Postoperative pneumonia is a common and devastating complication of hip fracture surgery in older individuals. This study aimed to determine the relationship between early postoperative hypoalbuminaemia and pneumonia after hip fracture surgery.

Patients and Methods: In this retrospective cohort study conducted at one centre, we reviewed the medical records of 1155 consecutive patients ( $>60$ years) who underwent hip fracture surgery. Multivariate logistic regression analysis was performed to identify the independent risk factors for postoperative pneumonia. After determining the cut-off value for postoperative serum albumin, the patients were divided into two groups according to the minimum serum albumin level recorded during the first two postoperative days: group A included patients with a minimum serum album level less than $3.0 \mathrm{~g} / \mathrm{dL}$ and group $\mathrm{B}$ included patients with a minimum serum album level of at least $3.0 \mathrm{~g} / \mathrm{dL}$. The prevalence of postoperative pneumonia was analysed using inverse probability of treatment weighting (IPTW) and propensity score matching (PSM) analyses.

Results: The incidence of postoperative pneumonia following hip fracture surgery was $5.1 \%$ $(\mathrm{n}=59)$. Age, cardiovascular disease, and early postoperative hypoalbuminaemia during the first two postoperative days were independent risk factors for postoperative pneumonia. Early postoperative hypoalbuminaemia was associated with postoperative pneumonia development in the PSM and IPTW analyses ( $\mathrm{P}=0.016$ and $<0.001$, respectively).

Conclusion: This study demonstrated that early postoperative hypoalbuminaemia is an independent risk factor for the development of postoperative pneumonia in patients undergoing hip fracture surgery.

Keywords: osteoporosis, osteoporotic fracture, albumin, complication

\section{Introduction}

As human life expectancy and the size of the aging population have increased, so too has the number of individuals vulnerable to hip fractures. ${ }^{1}$ Postoperative adverse complications are commonly associated with hip fracture surgeries, with a one-year mortality rate of $18 \% .^{2-10}$

Postoperative pneumonia is one of the most frequent and devastating complications after hip fracture surgery. ${ }^{11,12}$ Postoperative pneumonia is associated with an increased surgical mortality rate and prolonged length of hospital stay and its reported incidence ranged between $49 \%$ in patients with hip fractures. $^{13-17}$ 
Preoperative hypoalbuminaemia has been established as an independent predictor for postoperative complications and mortality after hip fracture surgery. ${ }^{13,17,18}$ However, given that the clinical importance of a perioperative decrease in serum albumin levels or early postoperative hypoalbuminaemia on postoperative morbidities has been emphasized, it is important to concentrate on perioperative or early postoperative changes in serum albumin levels and their relationship with postoperative outcomes. ${ }^{19-24}$

Several reports demonstrated the relationship between perioperative changes in serum albumin and the development of postoperative pneumonia in patients with gastric, colorectal, and lung cancers. ${ }^{19,21,22,24}$ However, scant studies investigated the risk factors of postoperative pneumonia in patients undergoing hip fracture surgery, and the relationship between early postoperative hypoalbuminaemia and postoperative pneumonia has never been delineated. ${ }^{25,26}$ Therefore, the purpose of this study was to investigate the incidence of postoperative pneumonia and identify risk factors associated with the development of this condition in patients who underwent hip fracture surgery.

\section{Patients and Methods Study Population}

This study was approved by the institutional review board of Korea University Medical Centre. A retrospective review was performed based on the medical records of 1228 patients who were aged $>60$ years and underwent surgery for hip fractures, including intertrochanteric and femoral neck fractures, at our hospital between January 1, 2010, and October 31, 2019. A single orthopaedic surgeon at our institution operated upon all patients via total joint arthroplasty or bipolar hemiarthroplasty for femoral neck fractures and via osteosynthesis using dynamic hip screws or intramedullary nail insertion for intertrochanteric fractures of the proximal femur. The exclusion criteria included patients who (1) who had pathological or periprosthetic fractures, (2) had X-ray and/or computed tomography-confirmed preoperative pneumonia and (3) had incomplete data or their data could not be obtained. Finally, a total of 1155 patients who underwent hip fracture surgery comprised the final study cohort (Figure 1). All patients were divided into two groups: group A included patients with a minimum serum albumin level less than $3.0 \mathrm{~g} /$ $\mathrm{dL}$ during the first two postoperative days and group $\mathrm{B}$ included patients with a minimum postoperative serum albumin level of at least $3.0 \mathrm{~g} / \mathrm{dL}$.

\section{Data Collection \\ Demographic Characteristics}

Baseline characteristics of patients and perioperative laboratory, clinical, and radiologic data were acquired from the computerised databases of our institution (Electronic Medical Record System and Picture Archiving Communication System). Baseline characteristics of each patient were collected, including age, sex, period from injury date to operation date, medication history including antiplatelets and anticoagulants, and comorbidities such as hypertension, diabetes mellitus, cardiovascular disease, cerebrovascular disease, chronic kidney disease, and chronic obstructive pulmonary disease.

\section{Perioperative Laboratory Findings and Clinical Data}

Serum haemoglobin $(\mathrm{Hb})$ and haematocrit (Hct) levels of patients were measured preoperatively and daily for 1 week postoperatively. The minimum $\mathrm{Hb}$ level observed during the first postoperative week was recorded. Estimated blood loss was calculated from the change in Hct level and the patient's estimated blood volume. The patient's blood volume was calculated according to Nadler's formula, and the total red blood cell (RBC) loss was calculated according to the Gross formula. ${ }^{27,28}$ According to the Gross formula, we calculated the total $\mathrm{RBC}$ loss during the first postoperative week. Since the Gross formula presents total blood loss in milliliters of RBCs, we converted this to milliliters of blood using the average of the preoperative and final Hct values.

Preoperative platelet counts and serum creatinine levels were also recorded. Patients' preoperative serum albumin levels were recorded and the minimum value observed during the first two postoperative days was recorded. The postoperative transfusion rate was recorded. The restrictive transfusion guidelines of our institution were followed: one unit of packed RBCs (derived from $400 \mathrm{~mL}$ of whole blood) was administered to patients with $\mathrm{Hb}$ levels of $6.0-6.9 \mathrm{~g} / \mathrm{dL}$, whereas two units of packed RBCs were administered to those with $\mathrm{Hb}$ levels of 5.0-5.9 g/dL. Transfusions were performed immediately after patients developed symptoms of anaemia and hypovolemia, including hypotension, tachycardia, tachypnoea, and dizziness. Intraoperative factors, including the type of surgical procedure (osteosynthesis or arthroplasty), duration of anaesthesia, and volume of fluid administered intraoperatively, were assessed using the intraoperative anaesthesia records. 


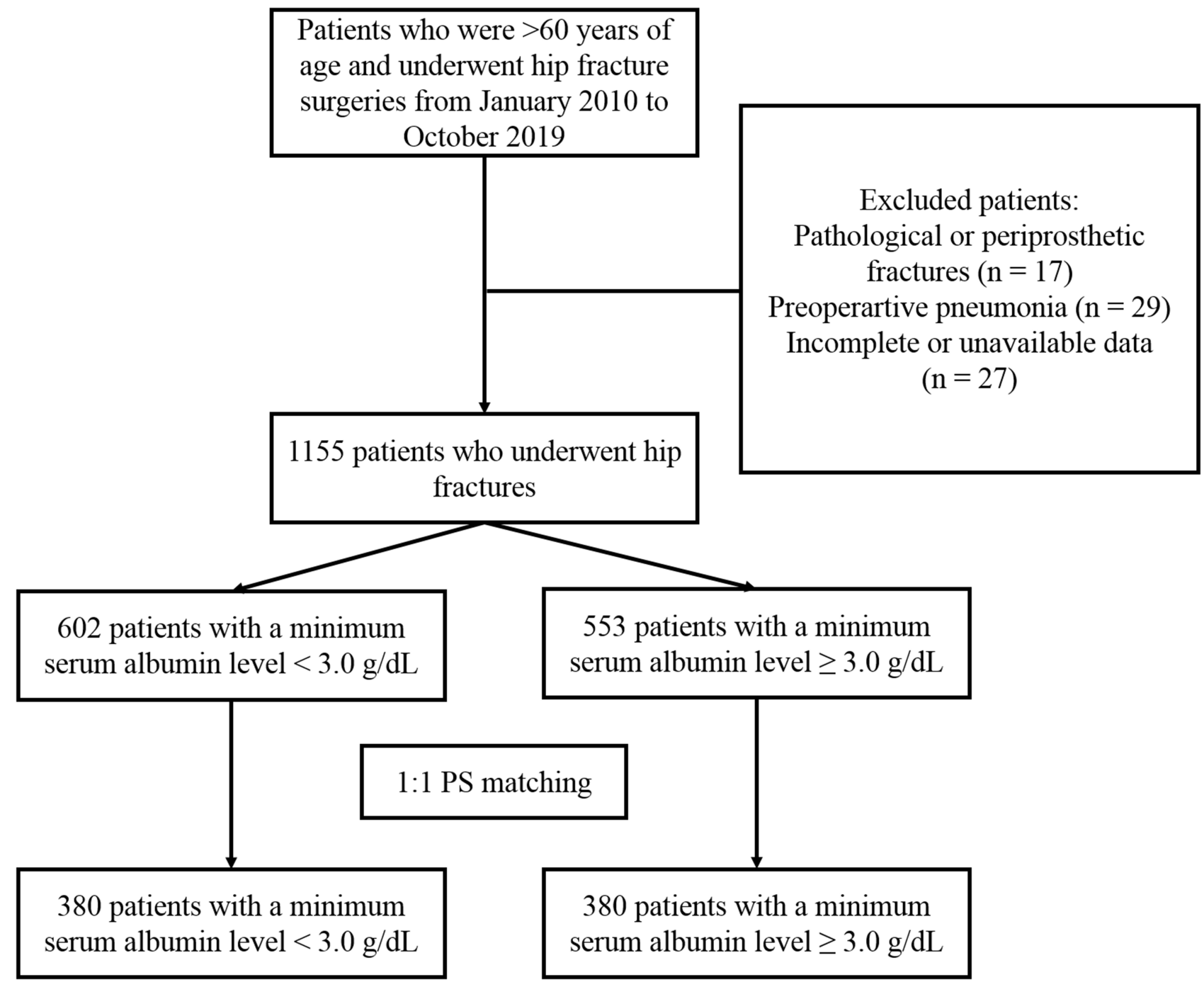

Figure I Flowchart illustrating the selection of the patients for this study.

\section{Definition of Postoperative Pneumonia}

The primary study outcome was the incidence of postoperative pneumonia during hospitalisation. Patients with postoperative pneumonia were defined as those who did not present with preoperative pneumonia and exhibited new infiltrations on the postoperative chest X-ray and/or computed tomography images. Patients were diagnosed with postoperative pneumonia when one of more of the following criteria were met: (1) presence of new and/or progressive and persistent respiratory symptoms, including coughing and purulent secretions; (2) presence of fever (body temperature $>38.0^{\circ} \mathrm{C}$ ) or hypothermia (body temperature $<36.0^{\circ} \mathrm{C}$ ); (3) physical examination showing lung consolidation and/or moist rale; (4) lab tests indicating leukocytosis (white cell count $>10 \times$ $10^{9} / \mathrm{L}$ ) or leukopenia (white cell count $<4 \times 10^{9} / \mathrm{L}$ ); and $(5)$ pathogen isolation from blood or sputum cultures. ${ }^{29-31}$

\section{Statistical Analysis}

All data were presented as means with standard deviations for continuous variables or percentages for categorical variables. Baseline characteristics and perioperative data were compared between the two groups using the Student's $t$-test and Fisher's exact test as appropriate. Multiple logistic regression analyses were performed to identify predictors of postoperative pneumonia and evaluate the impact of albumin level on the development of postoperative pneumonia. The model was adjusted for all covariates with a $\mathrm{P}$ value $<0.1$ in the univariate analysis. After confirming the significant relationship between early postoperative albumin level and the development of postoperative pneumonia, the cut-off value for postoperative albumin was determined based on the Youden index according to the receiver operating characteristic (ROC) 
curve. To reduce the effect of confounding factors between the two groups, we performed propensity score matching (PSM) and inverse probability of treatment weighting (IPTW). Propensity score was estimated using multiple logistic regression analysis with early postoperative hypoalbuminaemia as the dependent variable. All parameters presented in Table 1 except postoperative transfusion rate, length of stay, estimated blood loss, and minimum $\mathrm{Hb}$ level during the first postoperative week was used to determine the PS. After adjustment by PSM and IPTW, the balance between the two groups was assessed using the standardised mean difference. The association of early postoperative hypoalbuminaemia on postoperative pneumonia was evaluated using conditional logistic regression analysis or weighted logistic regression analysis. All $\mathrm{P}$ values $<0.05$ were deemed statistically significant. $\mathrm{R}$ software version 3.4 .2 and Statistical Product and Service Solutions (SPSS) software version

Table I Univariate and Multivariate Regression Analyses of Risk Factors for Postoperative Pneumonia

\begin{tabular}{|c|c|c|c|c|c|c|}
\hline \multirow[t]{2}{*}{ Variables } & \multicolumn{3}{|l|}{ Univariate } & \multicolumn{3}{|c|}{ Multivariate } \\
\hline & $\begin{array}{l}\text { Pneumonia } \\
(n=59)\end{array}$ & $\begin{array}{l}\text { Non-pneumonia } \\
(n=1096)\end{array}$ & P-value & OR & $95 \% \mathrm{Cl}$ & P-value \\
\hline \multicolumn{7}{|l|}{ Demographic characteristics } \\
\hline Sex (male/female) & $21(35.6) / 38(64.4)$ & $295(26.9) / 80 I(73.1)$ & 0.145 & & & \\
\hline Age (years) & $83.08 \pm 7.30$ & $77.90 \pm 10.05$ & $<0.001$ & 1.062 & $(1.022,1.103)$ & 0.002 \\
\hline BMI $\left(\mathrm{kg} / \mathrm{m}^{2}\right)$ & $22.32 \pm 3.43$ & $22.57 \pm 3.63$ & 0.673 & & & \\
\hline $\begin{array}{l}\text { Period between injury and operation date } \\
\text { (days) }\end{array}$ & $3.92 \pm 4.39$ & $3.72 \pm 3.14$ & 0.643 & & & \\
\hline HTN & $46(78.0)$ & $748(68.2)$ & 0.117 & & & \\
\hline DM & $21(35.6)$ & $388(35.4)$ & 0.976 & & & \\
\hline COPD & $4(6.8)$ & $54(4.9)$ & 0.526 & & & \\
\hline CKD & $10(16.9)$ & $140(12.8)$ & 0.353 & & & \\
\hline Cardiovascular disease & $17(28.8)$ & $170(15.5)$ & 0.007 & 2.03 & $(1.118,3.688)$ & 0.02 \\
\hline Cerebrovascular disease & II (I8.6) & $230(21.0)$ & 0.666 & & & \\
\hline \multicolumn{7}{|l|}{ Medication history } \\
\hline Antiplatelets & $20(33.9)$ & $371(33.9)$ & 0.994 & & & \\
\hline Anticoagulants & $6(10.2)$ & $66(6.0)$ & 0.199 & & & \\
\hline Type of surgery & & & 0.385 & & & \\
\hline Osteosynthesis & $33(55.9)$ & $675(61.6)$ & & & & \\
\hline Arthroplasty & $26(44.1)$ & $421(38.4)$ & & & & \\
\hline \multicolumn{7}{|l|}{ Laboratory findings } \\
\hline Preoperative $\mathrm{Hb}(\mathrm{g} / \mathrm{dL})$ & $11.62 \pm 1.57$ & $11.59 \pm 1.60$ & 0.856 & & & \\
\hline Preoperative Hct (\%) & $34.90 \pm 4.69$ & $34.67 \pm 4.69$ & 0.721 & & & \\
\hline Preoperative PIt $\left(\times 10^{9} / \mathrm{L}\right)$ & $216.31 \pm 98.02$ & $204.57 \pm 73.31$ & 0.369 & & & \\
\hline Preoperative $\mathrm{Cr}(\mathrm{mg} / \mathrm{dL})$ & $0.96 \pm 0.32$ & $0.96 \pm 0.77$ & 0.953 & & & \\
\hline \multicolumn{7}{|l|}{ Albumin $(g / d L)$} \\
\hline Preoperative & $3.59 \pm 0.45$ & $3.71 \pm 0.43$ & 0.04 & 1.012 & $(0.514,1.994)$ & 0.972 \\
\hline$<3.0$ during the first two postoperative days & $45(76.3)$ & $557(50.8)$ & $<0.001$ & 2.428 & $(1.26 I, 4.676)$ & 0.008 \\
\hline EBL during the first postoperative week $(\mathrm{mL})$ & $941.96 \pm 434.69$ & $893.41 \pm 373.88$ & 0.336 & & & \\
\hline $\begin{array}{l}\text { Minimum } \mathrm{Hb} \text { during the first postoperative } \\
\text { week }(\mathrm{g} / \mathrm{dL})\end{array}$ & $8.63 \pm 1.18$ & $8.54 \pm 1.21$ & 0.611 & & & \\
\hline Volume of fluid administered intraoperatively $(\mathrm{mL})$ & $701.69 \pm 409.79$ & $614.69 \pm 420.60$ & 0.121 & & & \\
\hline Anaesthesia time (minutes) & $121.44 \pm 31.12$ & $121.00 \pm 34.20$ & 0.924 & & & \\
\hline Length of stay (days) & $17.25 \pm 9.93$ & $15.77 \pm 11.18$ & 0.319 & & & \\
\hline Postoperative transfusion rate (\%) & $3(5.1)$ & $73(6.7)$ & 0.634 & & & \\
\hline
\end{tabular}

Note: Data are presented as mean \pm standard deviation or number $(\%)$

Abbreviations: OR, odds ratio; $\mathrm{Cl}$, confidence interval; BMI, body mass index; HTN, hypertension; DM, diabetes mellitus; COPD, chronic obstructive pulmonary disease; CKD, chronic kidney disease; Hb, haemoglobin; Hct, haematocrit; Plt, platelet count; Cr, creatinine; EBL, estimated blood loss. 
22.0 (IBM Corporation, Armonk, NY, USA) were used to handle and analyse the data.

\section{Results}

The incidence of pneumonia during hospitalisation among patients who underwent hip fracture surgeries was 5.1\% ( $\mathrm{n}=59$ out of 1155 patients). Multivariate regression analysis showed that age (odds ratio [OR], 1.062; 95\% confidence interval [CI], 1.022-1.103; $\mathrm{P}=0.002)$ and cardiovascular disease (OR, 2.03; 95\% CI, 1.118-3.688; $\mathrm{P}=0.02$ ) were determined to be independent risk factors for postoperative pneumonia (Table 1). Further, early postoperative rather than preoperative hypoalbuminemia was determined as an independent risk factor for postoperative pneumonia (OR, 2.428; 95\% CI, 1.261, 4.676; $\mathrm{P}=0.008$ ) (Table 1).

The optimal cut-off value of the minimal albumin level during the first two postoperative days that predicts postoperative pneumonia was determined to be $3.0 \mathrm{~g} / \mathrm{dL}$ (area under the ROC curve, 0.701). The demographic data and perioperative findings of patients with and without postoperative hypoalbuminaemia are summarised in Table 2. There were significant intergroup differences in sex, age, and preoperative $\mathrm{Hb}$, Hct, and albumin levels. In addition, patients in group A were more likely to have lower minimum $\mathrm{Hb}$ levels during the first postoperative week and a higher postoperative transfusion rate.

After adjustment by PSM and IPTW to reduce the effect of confounding factors other than early postoperative hypoalbuminemia, the two groups were found to be well balanced without any significant difference (Supplement S1). The association between postoperative pneumonia and early postoperative hypoalbuminaemia is summarised in Table 3. Even after PSM and IPTW analyses, the incidence of postoperative pneumonia was significantly associated with early postoperative hypoalbuminaemia during the first two postoperative days $(\mathrm{P}=0.016$ and $<0.001$, respectively).

\section{Discussion}

The principal finding of this study is that early postoperative hypoalbuminaemia (minimum serum albumin level less than $3.0 \mathrm{~g} / \mathrm{dL}$ during the first two postoperative days) was a significant predictor for postoperative pneumonia following hip fracture surgery even after PSM and IPTW analyses.

Pneumonia is one of the most devastating postoperative complications after general surgical procedures and is associated with a 3-fold increase in mortality. ${ }^{25,32}$ The incidence of postoperative pneumonia following hip fracture surgery is approximately $5 \% .^{25,26}$ Although little is known regarding risk factors for pneumonia after hip fracture surgery, several potential risk factors have been suggested, including sex, age, chronic obstructive pulmonary disease, low body mass index, anaemia, congestive heart failure, functional status, and surgery type. ${ }^{25,26}$ Recently, preoperative hypoalbuminaemia is reported to be associated with postoperative pneumonia following hip fracture surgery. ${ }^{17,26}$

Serum albumin level is used to assess protein-energy malnutrition in patients with hip fractures. ${ }^{33}$ Preoperative hypoalbuminaemia has been proven to be a significant risk factor for perioperative morbidity in patients undergoing orthopaedic surgery. ${ }^{13,17,18,33-36}$ However, if we concentrate only on preoperative albumin levels, we may not identify perioperative or early postoperative changes in albumin levels and their association with postoperative outcomes. A relationship between a postoperative decrease in serum albumin levels and adverse perioperative outcomes has been demonstrated in patients undergoing non-orthopaedic surgery. ${ }^{19,21,22,24}$ A postoperative decrease in serum albumin levels during the first three postoperative days is a significant predictor for shortterm complications following gastric cancer resection. ${ }^{22}$ Moreover, an early postoperative decrease in serum albumin levels was determined to be a risk factor for infectious complications including pneumonia in patients undergoing laparoscopic surgery for colorectal cancer. ${ }^{24}$ In addition, a reduction in serum albumin levels on postoperative day one was determined to be a predictor of postoperative pulmonary complications after thoracoscopic anatomical resection in patients with lung cancer. ${ }^{21}$ To the best of our knowledge, no studies have investigated the role of early postoperative hypoalbuminaemia in predicting postoperative pneumonia in patients undergoing hip fracture surgery. In this study, clinical and laboratory findings were evaluated to determine independent risk factors for postoperative pneumonia in patients undergoing hip fracture surgery. Multivariate analysis revealed that age, cardiovascular disease and early postoperative hypoalbuminaemia during the first two postoperative days were independent risk factors for postoperative pneumonia. Even after reducing the influence of possible confounding factors by PSM and IPTW analyses, early postoperative hypoalbuminaemia was found to be an independent risk factor for postoperative pneumonia. 
Table 2 Demographic and Perioperative Characteristics of Patients According to Minimum Serum Albumin Level During the First Two Postoperative Days

\begin{tabular}{|c|c|c|c|c|c|}
\hline \multirow[t]{2}{*}{ Variable } & \multirow[t]{2}{*}{ Total $(\mathrm{N}=$ I | 55) } & \multicolumn{2}{|c|}{$\begin{array}{l}\text { Minimum Albumin During the First Two } \\
\text { Postoperative Days (g/dL) }\end{array}$} & \multirow[t]{2}{*}{ P-value } & \multirow[t]{2}{*}{$\begin{array}{l}\text { Standardised } \\
\text { Difference }\end{array}$} \\
\hline & & $<3.0(n=602)$ & $\geq 3.0(n=553)$ & & \\
\hline \multicolumn{6}{|l|}{ Demographic characteristics } \\
\hline Sex (male/female) & $316(27.4) / 839(72.6)$ & $129(21.4) / 473(78.6)$ & $187(33.8) / 336(66.2)$ & $<0.001$ & 0.631 \\
\hline Age (years) & $78.16 \pm 9.99$ & $80.77 \pm 7.99$ & $75.33 \pm 11.13$ & $<0.001$ & 0.058 \\
\hline BMI $\left(\mathrm{kg} / \mathrm{m}^{2}\right)$ & $22.73 \pm 18.95$ & $22.55 \pm 24.44$ & $22.93 \pm 10.02$ & 0.740 & 0.001 \\
\hline $\begin{array}{l}\text { Period between injury and operation date } \\
\text { (days) }\end{array}$ & $3.73 \pm 3.22$ & $3.83 \pm 3.07$ & $3.61 \pm 3.37$ & 0.259 & 0.021 \\
\hline HTN & $794(68.7)$ & $418(69.4)$ & $376(68.0)$ & 0.597 & 0.067 \\
\hline DM & $409(35.4)$ & $205(34.1)$ & $204(36.9)$ & 0.314 & 0.124 \\
\hline COPD & $58(5.0)$ & $36(6.0)$ & $22(4.0)$ & 0.120 & 0.423 \\
\hline CKD & $150(13.0)$ & $84(14.0)$ & $66(11.9)$ & 0.308 & 0.179 \\
\hline Cardiovascular disease & $187(16.2)$ & $99(16.4)$ & $88(15.9)$ & 0.806 & 0.039 \\
\hline Cerebrovascular disease & $24 \mid(20.9)$ & $139(23.1)$ & $102(18.4)$ & 0.052 & 0.283 \\
\hline \multicolumn{6}{|l|}{ Medication history } \\
\hline Antiplatelets & 391 (33.9) & $210(34.9)$ & I8I (32.7) & 0.440 & 0.096 \\
\hline Anticoagulants & $72(6.2)$ & $43(7.1)$ & $29(5.2)$ & 0.182 & 0.326 \\
\hline Type of surgery & & & & 0.544 & 0.073 \\
\hline Osteosynthesis & $708(61.3)$ & $364(60.5)$ & $344(62.2)$ & & \\
\hline Arthroplasty & 447 (38.7) & $238(39.5)$ & $209(37.8)$ & & \\
\hline \multicolumn{6}{|l|}{ Laboratory findings } \\
\hline Preoperative $\mathrm{Hb}(\mathrm{g} / \mathrm{dL})$ & $11.59 \pm 1.60$ & $11.22 \pm 1.52$ & $11.99 \pm 1.59$ & $<0.001$ & 0.317 \\
\hline Preoperative Hct (\%) & $34.68 \pm 4.69$ & $33.67 \pm 4.48$ & $35.78 \pm 4.67$ & $<0.001$ & 0.101 \\
\hline Preoperative Plt $\left(\times 10^{9} / \mathrm{L}\right)$ & $205.17 \pm 74.76$ & $206.64 \pm 79.61$ & $203.57 \pm 69.15$ & 0.483 & 0.001 \\
\hline Preoperative $\mathrm{Cr}(\mathrm{mg} / \mathrm{dL})$ & $0.96 \pm 0.75$ & $0.93 \pm 0.57$ & $1.00 \pm 00.91$ & 0.150 & 0.112 \\
\hline Preoperative albumin $(\mathrm{g} / \mathrm{dL})$ & $3.70 \pm 0.43$ & $3.54 \pm 0.42$ & $3.88 \pm 0.38$ & $<0.001$ & 2.135 \\
\hline EBL during the first postoperative week $(\mathrm{mL})$ & $895.89 \pm 377.16$ & $894.13 \pm 376.81$ & $897.81 \pm 377.88$ & 0.868 & $<0.001$ \\
\hline $\begin{array}{l}\text { Minimum } \mathrm{Hb} \text { during the first postoperative } \\
\text { week }(\mathrm{g} / \mathrm{dL})\end{array}$ & $8.55 \pm 1.20$ & $8.18 \pm 1.03$ & $8.96 \pm 1.25$ & $<0.001$ & 0.594 \\
\hline $\begin{array}{l}\text { Volume of fluid administered intraoperatively } \\
(\mathrm{mL})\end{array}$ & $619.14 \pm 420.31$ & $632.24 \pm 425.97$ & $604.88 \pm 413.98$ & 0.269 & $<0.001$ \\
\hline Anaesthesia time (minutes) & $121.03 \pm 34.04$ & $122.44 \pm 36.96$ & $119.48 \pm 30.51$ & 0.137 & 0.003 \\
\hline Length of stay (days) & $15.85 \pm 11.12$ & $\mid 6.31 \pm 9.41$ & $15.35 \pm 12.72$ & 0.146 & 0.008 \\
\hline Postoperative transfusion rate (\%) & $76(6.6)$ & $55(9.1)$ & $21(3.8)$ & $<0.001$ & 0.892 \\
\hline
\end{tabular}

Note: Data are presented as mean \pm standard deviation or number $(\%)$

Abbreviations: BMI, body mass index; HTN, hypertension; DM, diabetes mellitus; COPD, chronic obstructive pulmonary disease; CKD, chronic kidney disease; Hb, haemoglobin; Hct, haematocrit; Plt, platelet count; Cr, creatinine; EBL, estimated blood loss.

The reduction in albumin levels after surgical trauma can be attributed to intra- and postoperative blood loss, perioperative haemodilution, and generalised inflammation. ${ }^{37-40}$ Moreover, postoperative hypoalbuminaemia may result from increased capillary permeability into the interstitial space. $^{37,38,40}$ Albumin protects the endothelial glycocalyx and maintains endothelial barrier function. ${ }^{41-43}$ Disruption of the endothelial glycocalyx has been demonstrated following surgical trauma or severe injury. ${ }^{44-46}$ Consequently, a vicious cycle of postoperative damage to the endothelial glycocalyx and hypoalbuminaemia may contribute to transcapillary albumin leakage and interstitial oedema in patients undergoing hip fracture surgery.

Hypoalbuminaemia may predispose patients to infection and other postoperative complications by promoting granuloma formation and reducing collagen synthesis, thus inhibiting the innate immune response. ${ }^{18,33,47}$ These highlight that the immune dysfunction in the postoperative period, expressed as early postoperative hypoalbuminemia, may have contributed to the development of postoperative pneumonia. 
Table 3 Comparison of the Incidence of Pneumonia According to Minimum Serum Albumin Level During the First Two Postoperative Days

\begin{tabular}{|c|c|c|c|c|c|c|c|c|c|}
\hline \multirow[t]{2}{*}{ Outcome } & \multirow{2}{*}{$\begin{array}{l}\text { Minimum Albumin During the } \\
\text { First Two Postoperative Days (g/ } \\
\text { dL) }\end{array}$} & \multicolumn{3}{|l|}{ Crude } & \multicolumn{2}{|c|}{ IPTW* } & \multicolumn{3}{|l|}{ PSM* } \\
\hline & & $\begin{array}{l}\text { Event/ } \\
\mathbf{N}\end{array}$ & $\begin{array}{l}\text { OR } \\
(95 \% \\
\text { Cl) }\end{array}$ & P-value & $\begin{array}{l}\text { OR } \\
(95 \% \\
\text { CI) }\end{array}$ & P-value & $\begin{array}{l}\text { Event/ } \\
\mathbf{N}\end{array}$ & $\begin{array}{l}\text { OR } \\
(95 \% \\
\text { CI) }\end{array}$ & P-value \\
\hline \multirow[t]{2}{*}{ Pneumonia } & $<3.0$ & $45 / 602$ & $\begin{array}{l}3.110 \\
(1.688 \\
5.732)\end{array}$ & $<0.00 \mathrm{I}^{\mathrm{a}}$ & $\begin{array}{l}3.053 \\
(1.958 \\
4.760)\end{array}$ & $<0.001^{b}$ & $19 / 223$ & $\begin{array}{l}3.111 \\
(1.237 \\
7.825)\end{array}$ & $0.016^{c}$ \\
\hline & $\geq 3.0$ & $14 / 553$ & & & & & $7 / 223$ & & \\
\hline
\end{tabular}

Notes: *The propensity score was calculated using a multiple logistic regression model that included all variables presented in Table I excluding postoperative transfusion rate, length of stay, estimated blood loss, and minimum $\mathrm{Hb}$ during the first postoperative week. ${ }^{\mathrm{a}} \mathrm{p}$-value by simple logistic regression. ${ }^{\mathrm{b}} \mathrm{p}$-value by weighted logistic regression. ' $\mathrm{p}$-value by conditional logistic regression

Abbreviations: IPTW, inverse probability of treatment weighting; PSM, propensity score matching

Recognising risk factors for postoperative complications is important for optimising perioperative patient care and predicting prognosis after surgery. This study is the first to demonstrate an association between early postoperative hypoalbuminaemia and the development of pneumonia after hip fracture surgery in older individuals. Therefore, monitoring serum albumin levels to detect early postoperative hypoalbuminaemia may aid in the early detection and prevention of postoperative pneumonia and patients with early postoperative hypoalbuminemia may benefit from more intense postoperative observation.

Several limitations of the current study should be noted. First, this was a retrospective observational analysis conducted at a single institution, which entails inherent limitations. Although we used PSM and IPTW analyses to adjust for the effects of confounding factors and reduce bias, confounding factors and unknown bias could not be entirely excluded. Second, we were unable to elucidate the mechanisms underlying the effect of early postoperative hypoalbuminaemia on postoperative pneumonia. Additionally, the causal relationship between early postoperative hypoalbuminaemia and pneumonia and the protective effect of albumin administration on prevention of postoperative pneumonia were not determined because this was an observational study. Therefore, large-scale multicentre prospective studies are needed to determine the causal relationship between the two conditions and to verify the protective effect of albumin administration.

\section{Conclusion}

This study suggests that early postoperative hypoalbuminaemia is an independent risk factor for the development of postoperative pneumonia in patients undergoing hip fracture surgery.

\section{Ethics Approval and Consent to Participate}

This study was reviewed and approved by the Institutional Board Review of Korea University Medical Centre (2020AN0081). This study was conducted in accordance with the Declaration of Helsinki. The consent was waived due to the retrospective nature of the study. We confirm that the privacy of the participants was saved, and the data were anonymized and maintained with confidentiality.

\section{Disclosure}

The authors report no conflicts of interest in this work.

\section{References}

1. Arias E. United States life tables, 2011. Natl Vital Stat Rep. 2015;64 (11):1-63.

2. Bass E, French DD, Bradham DD, Rubenstein LZ. Risk-adjusted mortality rates of elderly veterans with hip fractures. Ann Epidemiol. 2007;17 (7):514-519. doi:10.1016/j.annepidem.2006.12.004

3. Bennet SJ, Berry OM, Goddard J, Keating JF. Acute renal dysfunction following hip fracture. Injury. 2010;41(4):335-338. doi:10.1016/j. injury.2009.07.009

4. Choi HJ, Shin CS, Ha YC, et al. Burden of osteoporosis in adults in Korea: a national health insurance database study. $J$ Bone Miner Metab. 2012;30(1):54-58.

5. Kang BJ, Lee YK, Lee KW, Won SH, Ha YC, Koo KH. Mortality after hip fractures in nonagenarians. $J$ Bone Metab. 2012;19(2):83-86. doi:10.11005/jbm.2012.19.2.83

6. Lee YK, Kim JW, Lee MH, Moon KH, Koo KH. Trend in the age-adjusted incidence of hip fractures in south korea: systematic review. Clin Orthop Surg. 2017;9(4):420-423. doi:10.4055/cios.20 17.9.4.420 
7. Lee YK, Lee YJ, Ha YC, Koo KH. Five-year relative survival of patients with osteoporotic hip fracture. J Clin Endocrinol Metab. 2014;99(1):97-100. doi:10.1210/jc.2013-2352

8. Nho JH, Lee YK, Kim YS, Ha YC, Suh YS, Koo KH. Mobility and one-year mortality of stroke patients after hip-fracture surgery. J Orthop Sci. 2014;19(5):756-761. doi:10.1007/s00776-014-0593-4

9. Stewart NA, Chantrey J, Blankley SJ, Boulton C, Moran CG. Predictors of 5 year survival following hip fracture. Injury. 2011;42 (11):1253-1256. doi:10.1016/j.injury.2010.12.008

10. Yoon HK, Park C, Jang S, Jang S, Lee YK, Ha YC. Incidence and mortality following hip fracture in Korea. J Korean Med Sci. 2011;26 (8):1087-1092. doi: $10.3346 / \mathrm{jkms} .2011 .26 .8 .1087$

11. Lo IL, Siu CW, Tse HF, Lau TW, Leung F, Wong M. Pre-operative pulmonary assessment for patients with hip fracture. Osteoporos Int. 2010;21(Suppl 4):S579-586.

12. Vestergaard P, Rejnmark L, Mosekilde L. Increased mortality in patients with a hip fracture-effect of pre-morbid conditions and post-fracture complications. Osteoporos Int. 2007;18(12):15 83-1593. doi:10.1007/s00198-007-0403-3

13. Bohl DD, Shen MR, Hannon CP, Fillingham YA, Darrith B, Della Valle CJ. Serum albumin predicts survival and postoperative course following surgery for geriatric hip fracture. J Bone Joint Surg Am. 2017;99(24):2110-2118. doi:10.2106/JBJS.16.01620

14. Hu F, Jiang C, Shen J, Tang P, Wang Y. Preoperative predictors for mortality following hip fracture surgery: a systematic review and meta-analysis. Injury. 2012;43(6):676-685. doi:10.1016/j.injury.20 11.05 .017

15. Lawrence VA, Hilsenbeck SG, Noveck H, Poses RM, Carson JL. Medical complications and outcomes after hip fracture repair. Arch Intern Med. 2002;162(18):2053-2057.

16. Roche JJ, Wenn RT, Sahota O, Moran CG. Effect of comorbidities and postoperative complications on mortality after hip fracture in elderly people: prospective observational cohort study. BMJ. 2005;331(7529):1374. doi:10.1136/bmj.38643.663843.55

17. Wang Y, Li X, Ji Y, et al. Preoperative serum albumin level as a predictor of postoperative pneumonia after femoral neck fracture surgery in a geriatric population. Clin Interv Aging. 2019;14:2007-2016. doi:10.2147/CIA.S231736

18. Aldebeyan S, Nooh A, Aoude A, Weber MH, Harvey EJ. Hypoalbuminaemia-a marker of malnutrition and predictor of postoperative complications and mortality after hip fractures. Injury. 2017;48(2):436-440. doi:10.1016/j.injury.2016.12.016

19. Ge X, Dai X, Ding C, et al. Early postoperative decrease of serum albumin predicts surgical outcome in patients undergoing colorectal resection. Dis Colon Rectum. 2017;60(3):326-334.

20. Kang JS, Moon KH, Youn YH, Park JS, Ko SH, Jeon YS. Factors associated with postoperative acute kidney injury after hip fractures in elderly patients. J Orthop Surg. 2020;28(1):2309499019896237. doi: $10.1177 / 2309499019896237$

21. Li P, Li J, Lai Y, et al. Perioperative changes of serum albumin are a predictor of postoperative pulmonary complications in lung cancer patients: a retrospective cohort study. J Thorac Dis. 2018;10 (10):5755-5763. doi:10.21037/jtd.2018.09.113

22. Liu ZJ, Ge XL, Ai SC, et al. Postoperative decrease of serum albumin predicts short-term complications in patients undergoing gastric cancer resection. World J Gastroenterol. 2017;23(27):4978-4985. doi:10.3748/wjg.v23.i27.4978

23. Shin KH, Han SB. Early postoperative hypoalbuminemia is a risk factor for postoperative acute kidney injury following hip fracture surgery. Injury. 2018;49(8):1572-1576. doi:10.1016/j.injury.2018. 05.001

24. Wierdak M, Pisarska M, Kusnierz-Cabala B, et al. Changes in plasma albumin levels in early detection of infectious complications after laparoscopic colorectal cancer surgery with ERAS protocol. Surg Endosc. 2018;32(7):3225-3233.
25. Bohl DD, Sershon RA, Saltzman BM, Darrith B, Della Valle CJ. Incidence, risk factors, and clinical implications of pneumonia after surgery for geriatric hip fracture. J Arthroplasty. 2018;33(5):15521556 e1551. doi:10.1016/j.arth.2017.11.068

26. Lv H, Yin P, Long A, et al. Clinical characteristics and risk factors of postoperative pneumonia after hip fracture surgery: a prospective cohort study. Osteoporos Int. 2016;27(10):3001-3009.

27. Gross JB. Estimating allowable blood loss: corrected for dilution. Anesthesiology. 1983;58(3):277-280. doi:10.1097/00000542-198303 000-00016

28. Nadler SB, Hidalgo JH, Bloch T. Prediction of blood volume in normal human adults. Surgery. 1962;51(2):224-232.

29. American Thoracic S. Infectious diseases society of a. guidelines for the management of adults with hospital-acquired, ventilator-associated, and healthcare-associated pneumonia. Am J Respir Crit Care Med. 2005;171 (4):388-416

30. Cakir Edis E, Hatipoglu ON, Yilmam I, Eker A, Tansel O, Sut N. Hospital-acquired pneumonia developed in non-intensive care units. Respiration. 2009;78(4):416-422. doi:10.1159/000232392

31. Kieninger AN, Lipsett PA. Hospital-acquired pneumonia: pathophysiology, diagnosis, and treatment. Surg Clin North Am. 2009;89 (2):439-461, ix. doi:10.1016/j.suc.2008.11.001

32. Schein M. Postoperative pneumonia. Curr Surg. 2002;59 (6):540-548. doi:10.1016/S0149-7944(02)00661-X

33. O'Daly BJ, Walsh JC, Quinlan JF, et al. Serum albumin and total lymphocyte count as predictors of outcome in hip fractures. Clin Nutr. 2010;29(1):89-93. doi:10.1016/j.clnu.2009.07.007

34. Fu MC, Buerba RA, Grauer JN. Preoperative nutritional status as an adjunct predictor of major postoperative complications following anterior cervical discectomy and fusion. Clin Spine Surg. 2016;29 (4):167-172. doi:10.1097/BSD.0000000000000181

35. Huang R, Greenky M, Kerr GJ, Austin MS, Parvizi J. The effect of malnutrition on patients undergoing elective joint arthroplasty. $J \quad$ Arthroplasty. 2013;28(8 Suppl):21-24. doi:10.1016/j. arth.2013.05.038

36. Peacock MR, Farber A, Eslami MH, et al. Hypoalbuminemia predicts perioperative morbidity and mortality after infrainguinal lower extremity bypass for critical limb ischemia. Ann Vasc Surg. 2017;41 (169175):e164. doi:10.1016/j.avsg.2016.08.043

37. Fleck A, Raines G, Hawker F, et al. Increased vascular permeability: a major cause of hypoalbuminaemia in disease and injury. Lancet. 1985;1(8432):781-784. doi:10.1016/S0140-6736(85)91447-3

38. Hubner M, Mantziari S, Demartines N, Pralong F, Coti-Bertrand P, Schafer M. Postoperative Albumin Drop Is a Marker for Surgical Stress and a Predictor for Clinical Outcome: A Pilot Study. Gastroenterol Res Pract. 2016;2016:8743187. doi:10.1155/2016/ 8743187

39. Lee JI, Kwon M, Roh JL, et al. Postoperative hypoalbuminemia as a risk factor for surgical site infection after oral cancer surgery. Oral Dis. 2015;21(2):178-184. doi:10.1111/odi.12232

40. Ryan AM, Hearty A, Prichard RS, Cunningham A, Rowley SP, Reynolds JV. Association of hypoalbuminemia on the first postoperative day and complications following esophagectomy. J Gastrointest Surg. 2007;11(10):1355-1360. doi:10.1007/s11605007-0223-y

41. Alphonsus CS, Rodseth RN. The endothelial glycocalyx: a review of the vascular barrier. Anaesthesia. 2014;69(7):777-784. doi:10.1111/ anae. 12661

42. Jacob M, Paul O, Mehringer L, et al. Albumin augmentation improves condition of guinea pig hearts after $4 \mathrm{hr}$ of cold ischemia. Transplantation. 2009;87(7):956-965.

43. Stevens AP, Hlady V, Dull RO. Fluorescence correlation spectroscopy can probe albumin dynamics inside lung endothelial glycocalyx. Am J Physiol Lung Cell Mol Physiol. 2007;293(2): L328-335. doi:10.1152/ajplung.00390.2006 
44. Arthur A, McCall PJ, Jolly L, Kinsella J, Kirk A, Shelley BG. Endothelial glycocalyx layer shedding following lung resection. Biomark Med. 2016;10(10):1033-1038. doi:10.2217/bmm-20160163

45. Rahbar E, Cardenas JC, Baimukanova G, et al. Endothelial glycocalyx shedding and vascular permeability in severely injured trauma patients. J Transl Med. 2015;13:117. doi:10.1186/s12967015-0481-5
46. Rehm M, Bruegger D, Christ F, et al. Shedding of the endothelial glycocalyx in patients undergoing major vascular surgery with global and regional ischemia. Circulation. 2007;116(17):1896-1906. doi:10. 1161/CIRCULATIONAHA.106.684852

47. Otranto M, Souza-Netto I, Aguila MB, Monte-Alto-Costa A. Male and female rats with severe protein restriction present delayed wound healing. Appl Physiol Nutr Metab. 2009;34(6):1023-1031. doi:10.1139/H09-100

\section{Publish your work in this journal}

Clinical Interventions in Aging is an international, peer-reviewed journal focusing on evidence-based reports on the value or lack thereof of treatments intended to prevent or delay the onset of maladaptive correlates of aging in human beings. This journal is indexed on PubMed Central, MedLine, CAS, Scopus and the Elsevier
Bibliographic databases. The manuscript management system is completely online and includes a very quick and fair peer-review system, which is all easy to use. Visit http://www.dovepress.com/ testimonials.php to read real quotes from published authors.

Submit your manuscript here: https://www.dovepress.com/clinical-interventions-in-aging-journal 